
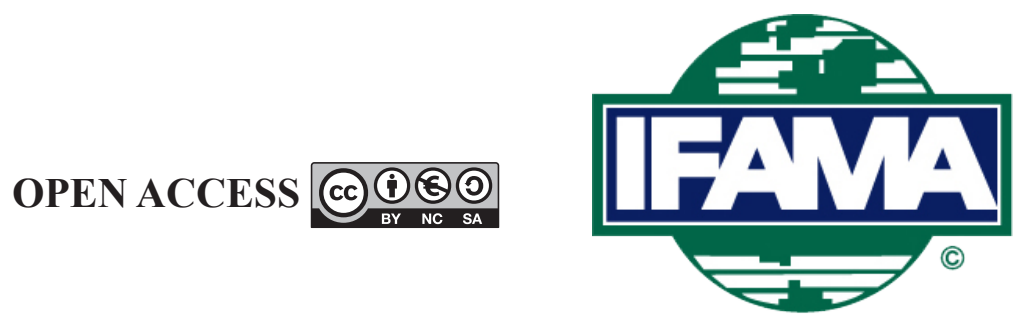

International Food and Agribusiness Management Review

Volume 23, Issue 5, 2020; DOI: 10.22434/IFAMR2019.0181

Received: 5 November 2019 / Accepted: 9 February 2020

Special issue: New and sustainable food and agribusiness management models

\title{
Reviewing studies of radio frequency identification applications in supply chain for food safety REVIEW ARTICLE
}

\author{
Xiao-Wei Wen ${ }^{\oplus a, b}$, Janita Marlin ${ }^{\mathrm{c}}$, Zhi-Jian Wen ${ }^{\mathrm{d}}$ and Zhao-Hui Yang ${ }^{\mathrm{a}}$ \\ a Professor, College of Economics and Management, South China \\ Agricultural University, Guangzhou 510642, China P.R. \\ ${ }^{b}$ Professor, Loonguard Research Institute, Guangzhou 510642, China P.R. \\ ${ }^{c}$ Lecturer, College of Management, I-Shou University, Taiwan \& Economic Faculty, \\ Universitas Internasional Batam, Batam City 29442, Indonesia \\ ${ }^{d}$ Student, College of Artificial Intelligence, Changchun University of \\ Science and Technology, Changchun 130022, China P.R.
}

\begin{abstract}
Food security and safety are central topics worth to be investigated by academicians and practitioners. Radio frequency identification (RFID) is more than a tool with wireless microchips for identification but a facilitator that increases the traceability of food products and better business model innovations. This paper reviews the literature of issues regarding RFID in the context of food supply chains (e.g. issues on the feasibility of RFID for better food traceability). We make a careful review of 13 papers published in 9 SSCI journals and conferences published from 2004 to 2016. Findings are discussed for offering suggestions that could improve the research streams and practices.
\end{abstract}

Keywords: radio frequency identification, food supply chain, literature review JEL code: $\mathrm{O} 30$

(1) Corresponding author: wenxiaowei49@gmail.com / wxwcn@scau.edu.cn 


\section{Introduction}

The food industry encountered a great impact on food crises in the last decade, it includes quantity matters and also the cases of food contamination that got a lot of attention from the public (Kelepouris et al., 2007). One of the mature industries is food industry, food, and beverage processing. Most of the food and beverage local processors are come from small or micro-sized enterprises, though there are also some large companies that dominate the market. The food and beverage industry is always a popular industry even to some foreign investors that want to enter the market. The investments from local and foreign investors play a vital role in export and import activities in emerging countries.

Sometimes farmers face some difficulties in the national food production chain that causes that they will need to import raw materials from abroad in order to fulfill the demand. Import matters also become endless homework in local food and beverage processors. For example, in 2012 and 2013 Rupiah, the currency of Indonesia experienced a great depreciation due to the fluctuating global prices of ingredients because they relied so much on imports of wheat, sugar, milk, and other ingredients.

A lot of food-related accidents keep reminding us of the importance of food safety and food quality (Choe et al., 2009). Along with the times, the consumption of healthy food and frozen food is increasing. There are some young population more concerns about having some nutritional drink, vitamin, minerals, etc. There are also some groups of people that only concern to find fast and convenience food due to urbanization and the growing of office workers. The healthy and frozen food may be also processed by local food and beverage processors or even from foreign investors. But they also face the same problems, such as the safety of the source of ingredients and technology development to ensure their quality and credibility as a good food producer.

The imported product is unavoidable so that we can keep our food safety and security. Imports of ingredients and processed foodstuffs will still be needed as long as developing countries cannot provide by their own. Local food processors need to figure out how to keep their costs and improve their competitiveness. One of the ways to increase food safety and security is through improvement in supply chain management. Innovation and investment of information technology is an important and significant improvement in supply chain management (Bowersox and Daugherty, 1995). Information technology innovation and investment may enhance the development of new equipment and optimized processes that can alleviate the cost and strengthen product quality.

The adoption of new technology (e.g. sensors) for food production is very important (Adley, 2014). In various industries, new technology in supply chain can alter or affect the core processes and mechanisms that organizations in an industry rely on when trying to create strategic values (Boyson et al., 2003; Cheng et al., 2001; Manthou et al., 2004). Hence, the technologies such as the global positioning system tracking and radio frequency identification (RFID) that are already common for advanced countries (Zelbst et al., 2010), and can generate impacts and define/redefine foods even agriculture business models. Furthermore, the strategic changes in business models deals with more than technology itself (Chesbrough, 2007), but we should go beyond it to investigate into the functioning mechanisms between the technology and the business model. This is exactly what this paper sets to achieve. For fulfilling such goal, scholarly works need to focus on the most potential technologies. RFID is the most discussed technology of food supply chain with $73.68 \%$ of the review papers discuss the food traceability using this technology (Zhong et al., 2017).

The goal of this paper is to cover the organization's antecedents of supply chain technology adoption especially for RFID of the food industry. During the last decade, the food supply chain has received numerously attention (Bigliardi and Bottani, 2010; Ngai et al., 2008a). So, knowing how to improve our food supply chain with the adoption of information technology innovation and investment will be our focus homework. Note that the discussion of the applicability of RFID in this paper is not food-technology-oriented but marketing-oriented Such distinction is for justifying our paper's position and methodology used here. 


\section{Materials and methods}

The goal of the study is to grasp the current situation of RFID research and the antecedents of supply chain adoption in the food industry especially toward food security and food safety, bring out some useful recommendation to RFID practitioners and researchers, and also future directions for RFID research by analyzing the previous published literature. We limit our research scope to the year 2006-2014, as RFID research is classified as comparatively recent. This 9-year period is presumed to be the proxy of the RFID research in the food industry.

To exhaust the study goal, we select the subsequent electronic databases in performing a literature search, such as EBSCO Business Source Complete (EBSCO-BSC), ProQuest Center, ScienceDirect Online (SDOL), Emerald Insight, and Web of Science (SSCI). We searched for data by using these keywords: 'RFID', 'Radio Frequency Identification', 'supply chain', and 'food industry'. The scope of the search was set to include the titles, keywords, and abstracts of the studies. Third, we selected 2004-2016 as the year of publication since 2004, when the diffusion of wireless sensors and sensor networks in the food industry yet at the starting stage. Wang et al. (2006) subsumed the application of wireless sensors and sensor networks into five categories, one of them is traceability systems that strongly related to food safety. In order to eliminate articles that have not correspond to RFID in the full industry, the full text of each article was considered. Through the procedures, a final effective sample of 13 studies was sorted and used for further analyses.

Before deciding a judgment regarding each literature inclusion as a participated literature, each literature was included beyond the search process was severely investigated deciding on its inclusion in the survey. Every successful case of RFID adoption in the food industry of the sample studies will be analyzed and included in this paper.

\section{Results}

From Table 1 we can find that the highest citation regarding RFID topics is about the technology of RFID. But the literature about the RFID system and its usefulness to improve traceability and supply chain management are keeping increasing and earn more citations also. The academic concerns in the RFID system especially in food supply chain have delivered a rapid accretion in the number of related literature. The largest possibility is because food safety and security are really related to human life and the using of RFID in improving traceability is something that human really need to increase their life quality.

In supply chain management, food products during the whole distribution and storage processes can be tracked through RFID tags. RFID tags are small and easy to attach to the food, moreover, its reading phase is fast and automated (Regattieri et al., 2007). RFID as the 'next generation barcode' has been widely used for a diversity of applications in many sectors (Kelepouris et al., 2007). In the food industry, most of the supply chain parties are small or micro-sized enterprises, so the cost-effectiveness of RFID technology adoption still needs some consideration.

\subsection{Advantages of radio frequency identification in food supply chain management}

In the implementation of RFID especially in the food sector, based on the literature we found some advantages such as:

- RFID technology can capture product point information almost without any labor costs endure (Kelepouris et al., 2007).

- There are uniform electronic product codes for all traded technical resource units among partners, so we do not need to map the data and can enjoy an optimum data quality with large memory size (Aung and Chang, 2014; Kelepouris et al., 2007). 
Table 1. Summary of radio frequency identification overview literature in supply chain management. ${ }^{1}$

\begin{tabular}{|c|c|c|c|c|}
\hline Serial & $\begin{array}{l}\text { Authors and year of } \\
\text { publication }\end{array}$ & Category & Emphasis & $\begin{array}{l}\text { \# of } \\
\text { citation }\end{array}$ \\
\hline 1 & Weis et al. (2004) & RFID Technology & $\begin{array}{l}\text { Technologies of low-cost RFID, security and } \\
\text { privacy risk, and suggestion of some security } \\
\text { mechanism }\end{array}$ & 2,000 \\
\hline 2 & Landt (2005) & RFID Technology & The history of RFID & 1,115 \\
\hline 3 & Sarma et al. (2002) & RFID Technology & $\begin{array}{l}\text { RFID systems, security, and privacy } \\
\text { implications }\end{array}$ & 1,085 \\
\hline 4 & Angeles (2005) & RFID Systems & $\begin{array}{l}\text { Applications and implementation issues of } \\
\text { RFID technologies }\end{array}$ & 961 \\
\hline 5 & Weinstein (2005) & RFID Technology & $\begin{array}{l}\text { The application of RFID, issue, and challenge } \\
\text { of RFID }\end{array}$ & 772 \\
\hline 6 & Ngai et al. (2008a) & RFID Systems & Literature review 1995-2005 of RFID & 696 \\
\hline 7 & Roberts (2006) & RFID Technology & RFID history, technology, and adoption & 656 \\
\hline 8 & Garfinkel et al. (2005) & RFID Technology & $\begin{array}{l}\text { Privacy problem and solution about RFID } \\
\text { application }\end{array}$ & 611 \\
\hline 9 & Wu et al (2006) & RFID Technology & RFID adoption challenge & 524 \\
\hline 10 & Sarac et al. (2010) & RFID Systems & $\begin{array}{l}\text { Literature review of RFID implementation on } \\
\text { supply chain }\end{array}$ & 469 \\
\hline 11 & Asif (2005) & RFID Systems & $\begin{array}{l}\text { Application of RFID in the supply chain and } \\
\text { consideration to adopt RFID }\end{array}$ & 469 \\
\hline 12 & Michael and McCathie (2005) & RFID Technology & Pros and cons to the application of RFID & 441 \\
\hline 13 & Tajima (2007) & RFID Systems & $\begin{array}{l}\text { The strategic value of RFID in supply chain } \\
\text { management }\end{array}$ & 418 \\
\hline 14 & Domdouzis et al. (2007) & RFID Technology & History and current technology of RFID & 348 \\
\hline 15 & Kelepouris et al. (2007) & RFID Systems & $\begin{array}{l}\text { Use of RFID to increase traceability in the } \\
\text { food supply chain }\end{array}$ & 340 \\
\hline 16 & Bottani and Rizzi (2008) & RFID Systems & $\begin{array}{l}\text { Improving the FMCG supply chain through } \\
\text { RFID technology and EPC system }\end{array}$ & 332 \\
\hline 17 & Prater et al. (2005) & RFID Systems & Use of RFID in the grocery industry & 332 \\
\hline 18 & Attaran (2007) & RFID Systems & $\begin{array}{l}\text { Implementation issues, application in various } \\
\text { industries, products, opportunities, and } \\
\text { challenges of RFID }\end{array}$ & 318 \\
\hline 19 & Rao (1999) & RFID Technology & Application of RFID and its subsystem & 205 \\
\hline 20 & Wang et al. (2007) & RFID Technology & $\begin{array}{l}\text { Dynamic supply chain management with } \\
\text { the implementation of mobile construction } \\
\text { RFID-based }\end{array}$ & 201 \\
\hline 21 & Visich et al. (2009) & RFID Systems & $\begin{array}{l}\text { Application RFID on supply chain } \\
\text { management }\end{array}$ & 136 \\
\hline 22 & Yagi et al. (2005) & RFID Technology & Application of RFID for construction & 123 \\
\hline
\end{tabular}


- The deployment of the RFID information system is a sum of investment that really does not cost much in RFID reader tools and wireless connection with concentrated information systems (Kelepouris et al., 2007).

- It improved the management of perishable items because we have a better knowledge of items movements, so it can reduce waste and we serve better in satisfying customer needs (Regattieri et al., 2007).

- It improved the tracking and tracing of quality products. Through the RFID systems we able to trace and identify the defective products information and it helps us react to any quality problem and enables large-scale sequenced identification of every single product in the supply chain (Aung and Chang, 2014; Kelepouris et al., 2007; Regattieri et al., 2007; Zhang and Li, 2012).

- In the case of deficiency, the information of deficiency can be easily drawn from the centralized information system and information about internal processes is obtained effectively because of uniform modeling (Kelepouris et al., 2007).

- It improved the management of product recalls. RFID can increase efficiency in recalling procedures and help producers and distributors to dampen loss by trace product routings (Regattieri et al., 2007).

- RFID can incorporate supply chains and its networks well and extend facilities for constructed extra added value. Cooperation among all of the parties in implementing the traceability system is really needed through labeling activities or at an extended level, such as branding (Zhang and Li, 2012).

- Secure food safety. Through following the national regulation of food standard, it will increase food quality and food standard. By every party in the supply chain follow the standard, and some even do the labeling, the coherence that is resulted from the RFID technology in the supply chain will exacerbate the process of production and reduce the risk of food quality inadequacy (Zhang and Li, 2012).

According to Kelepouris et al. (2007), the ante of RFID in complying the traceability necessities of a product are:

\section{- Item identification}

Since every item has its own unique identification serial through the RFID tag, it makes every item is traceable. Identification starts from the item level, and a unique code has been carried by each product in the whole chain (Kelepouris et al., 2007). Although the management cost may increase because we increase the traceability resolution, the accuracy and complexity of the information are increasing due to this change. It is unavoidable if we want to increase the accuracy and traceability resolution because there are some related costs that we need to trade-off for.

\section{- Bill of lots - batch distribution}

For every specific batch that will be produced, they need to register it in items, cases, or pallets. As they are employing wireless identification, they can have detection and identification that work automatically of lots that are used in a certain batch of product (Kelepouris et al., 2007).

\section{- Operations and capacity units}

RFID makes a whole production cycle can be recorded. Through RFID we can know under which the operation has been performed by the variables and their values. Deviation in the material input specification will bring out the anomaly in the material output itemization and the capacity units also need to be registered to prevent a food shortage that may relate to capacity situations happen (Kelepouris et al., 2007). 


\section{- Item observations}

With RFID, information about the product location can be recorded throughout the supply chain. We can know the exact route of the products from the farm until they arrive at the retail store and predict both the capacity units of the product and the processes that have been added to (Kelepouris et al., 2007). According to Kelepouris et al. (2007), the information of location, timestamps, and item identity at the level that item will be used, are the information that should be provided by each observation, to increase the accurateness in observing item within the chain with a low level of the labor costs.

\section{- Link management and data retrieval}

RFID technology can manage the data well through real-time updates and results in significant cost decrease and better data quality.

\subsection{Disadvantages of radio frequency identification in food supply chain management}

If we want to implement RFID in a supply chain, pursuant to Ngai et al. (2008b) some challenges are waiting for us. First, RFID expertise for deployment, we need to train our employees in RFID technology. Second, we need to convince the management that RFID will increase our competitive advantage and gaining their commitment. Third, the cost of implement RFID is high, we have to consider the substantial investment cost in hardware, software, middleware, tags, and the cost of combining the RFID-based system with the legacy systems, of consultancy fees, and employee training. Last, both RFID hardware and software in Asian markets source from the US with limited technical support.

Aung and Chang (2014) also listed some disadvantages in the adoption of RFID technology, such as:

- for data collection, RFID technology relies on reader;

- communication cannot be initiated by a tag;

- within the devices of RFID, there is no cooperation;

- data can be read within one hop;

- it is still considered as a high-priced investment, regarding its cost of adoption;

- limited capability for environmental sensing.

Table 2 shows the characteristics of the 13 sample studies. For this research, we consider eight journals listed on the SSCI and one conference paper. Each of the Journal of Food Engineering and Computers and Electronics in Agriculture contributes 23.08\% in this literature review. RFID has really related to food engineering and technology in agriculture, that is why there are a lot of literature regarding food problems are published in these journals.

Table 2. Sampled articles.

\begin{tabular}{llcc}
\hline Serial & Journal title & No. of papers & Percentage \\
\hline 1 & Journal of Food Engineering & 3 & $23.08 \%$ \\
2 & Computers and Electronics in Agriculture & 3 & $23.08 \%$ \\
3 & Information Systems Frontiers & 1 & $7.69 \%$ \\
4 & Industrial Management \& Data Systems & 1 & $7.69 \%$ \\
5 & Food Control & 1 & $7.69 \%$ \\
6 & International Journal of Production Economics & 1 & $7.69 \%$ \\
7 & Supply Chain Management-An International Journal & 1 & $7.69 \%$ \\
8 & Journal of Food Science & 1 & $7.69 \%$ \\
9 & Conference - Physics Procedia & 1 & $7.70 \%$ \\
Total & & 13 & $100 \%$ \\
\hline
\end{tabular}

International Food and Agribusiness Management Review 
Table 3 sums up the key studies classified by 'system design', 'industry overview', and 'benefit analysis'. Most of the studies are in the industry overview type which give the description of general situation of food traceability systems (Choe et al., 2009; Dabbene and Gay, 2011; Jedermann et al., 2009; Kelepouris et al., 2007; Prater et al., 2005; Wang et al., 2006). The research that we classified as a system design type suggests that a preserved food distribution channel and system can be erected by a particular traceability model in food supply chains (Barge et al., 2014; Hong et al., 2011; Ngai et al., 2008b; Regattieri et al., 2007;). Only the study of Zhang and $\mathrm{Li}$ (2012) indicates how food safety can be elevated through a traceability system. In their study, Zhang and $\mathrm{Li}$ (2012) also provide drivers for traceability of supply chain and implementation intelligence of RFID in the food supply chain of agriculture area.

Table 4 shows the most influencing antecedent of supply chain technology adoption is cost and benefit consideration. Wang et al. (2006) believe that without plurality and high cost that will be needed in large plants, adopting the supply chain technology will move faster. The application of RFID needs to keep stable between the amount of cost and the level of product safety requirements, otherwise, even the RFID has a lot of advantages toward the supply chain, considerations whether will adopt the RFID or not will not be made (Zhang and Li, 2012).

Management vision and commitment also a great determinant of supply chain management adoption. If the management of companies that processing food can consider traceability as a chance to evolution and a way to improve process control it will be better (Regattieri et al., 2007). Obtaining commitment of management is

Table 3. Literature on food traceability system.

\begin{tabular}{|c|c|c|}
\hline Category & Author & Scope of the study \\
\hline \multirow[t]{7}{*}{ Industry overview } & Dabbene and Gay (2011) & Recall cost to evaluate and optimize the traceability system \\
\hline & Jedermann et al. (2009) & Temperature monitoring \\
\hline & Wang et al. (2006) & $\begin{array}{l}\text { Environmental surveillance, maintain the quality of agriculture, } \\
\text { machines and processes management, establish and create } \\
\text { automation within the traceability system }\end{array}$ \\
\hline & Choe et al. (2009) & $\begin{array}{l}\text { How food traceability system can reduce customer's uncertainty } \\
\text { and facilitates the food transactions }\end{array}$ \\
\hline & Kelepouris et al. (2007) & RFID system architecture \\
\hline & Kumar et al. (2009) & Terminology and implementation of RFID in the food industry \\
\hline & Prater et al. (2005) & Grocery supply chain \\
\hline \multirow[t]{4}{*}{ System design } & Regattieri et al. (2007) & Expensive cheese \\
\hline & Hong et al. (2011) & Convenience stores \\
\hline & Barge et al. (2014) & Long-ripened cheese \\
\hline & Ngai et al. (2008) & Sushi restaurant \\
\hline Benefit analysis & Zhang and $\mathrm{Li}(2012)$ & Agri-food supply chain \\
\hline
\end{tabular}

Table 4. Antecedents of supply chain technology adoption.

\begin{tabular}{lll}
\hline Factor & Number & Frequency (\%) \\
\hline Cost and benefit consideration & 4 & 26.67 \\
Management vision and commitment & 3 & 20.00 \\
Customer behavior & 3 & 20.00 \\
Supply chain improvement & 2 & 13.33 \\
Decentralized data management system & 1 & 6.67 \\
Supply chain member pressure & 1 & 6.67 \\
Uniform standardization & 1 & 6.67 \\
\hline
\end{tabular}


one of the challenging tasks in the application of RFID and considerations of return on investment of RFID also will have a great impact on the management commitment (Ngai et al., 2008b). Prater et al. (2005) tell us without management vision and commitment, the adoption of new technology will lack a driving reason, but if with support of management vision and commitment, it will entrench the business practice.

The reason that Dabbene and Gay (2011) develop a set of procedures for assessing and intensifying the enforcement of a traceability system is to minimize the amount of recall product that may affect publicity and impression customers toward the quality of the product. Choe et al. (2009) studies about how food traceability systems can reduce customer's insecurity and eases the transactions of food. The studies find out that the reason that a company wants to employ the food traceability system is to alleviate the insecurity of the customer. The trustworthiness, serenity, and belief in the food system, are the benefits that traceability can give to the customer (Aung and Chang, 2014). Through traceability it will satisfy the customer demand for real-time information about the products and will result in a competitive advantage of the company.

Major food companies need supply chain management and logistics improvements to achieve their cost and benefit objective and also maintain their traceability efficiency level to ensure their quality and safety. So, they need RFID to improve their supply chain management through labor derivation, automation, fully informed in inventory locations, mitigate the risk of inventory drawback, and easier supply chain management which is the advantage of adopting RFID (Barge et al., 2014). RFID is a useful tool for intensifying the supervision within the transport process and help us find out the source of possible problems that may happen in the supply chain (Jedermann et al., 2009).

When huge volumes of data are being entailed by a corporate information technology system that is troublesome to handle, that cannot be handled by manual assessment and transmission over mobile networks, they can implement decentralized data management through RFID (Jedermann et al., 2009). The implementation of RFID by the US Department of Defense and global retailers such as WalMart, Metro, Tesco, etc. clearly define that their implementation of RFID can pressure their suppliers and make this technology become a market mandate (Kelepouris et al., 2007). Establishing a uniform standard of implementing RFID could lead to escalating the adoption of this technology in the food industry because sometimes a tag of certain frequency cannot be readable in another country (Kumar et al., 2009). The uniform standards can help the company to adopt RFID in an easier way.

\section{Discussion}

As the rising demand for food security and safety, control of the food product inspection has become compulsory and more demanding. Systematic discovery, labeling, and transcription of quality and safety criteria will be the main focuses during the entire food production chain from the field until the product can be served on the customer's tables. These high traceability requirements are demanded to reduce the realized risks associated with the food served (Choe et al., 2009; Wang et al., 2006). From the review we can say that RFID is the best tool to serve traceability and provide the information that each supply chain party needs to ensure food safety and security. It will become a trend.

RFID can increase the manufacturing process, distributing process, and restocking process in supply chain management. RFID has so many unique capabilities such as increasing the flexibility of planning of production activities, materials, tools or spare parts become more transparent for tracking, improving the maintenance process to become more efficient, reducing labor costs and minimizing related human errors. So, RFID will increase the traceability of products and enhance food safety and security at the same time.

Even though there are a lot of advantages from adopting RFID, but it still will change the existing progress. So, it is proper to do some feasibility studies first before decision to apply tags and readers on their food processing supply chain. Based on the review that had been conducted before making a decision either implement RFID or not, we must consider the following conditions. First, evaluate the business case, it is 
worth or not to do the investment in RFID. Second, develop an evident, detail, and workable design plan. Third, master the way of works of RFID. Fourth, knowing that will have a large number of remote preservation activities, and plan for it. Fifth, consider your network's capability, your decision in implementing RFID maybe will cause your network need to implement it also. Sixth, knowing the RFID risks and be prepared on it. Seventh, the flexibility of supply chain process and technical design are required. Eight, choose reliable security measures. Ninth, be aware of the privacy issues. Tenth, evaluate the usefulness of RFID, is it fit for companies' visions, missions, goals, and another strategic issue.

The decision of the certain company either to adopt the RFID or not will be influenced by the cost and benefit consideration, management vision and commitment, customer behavior at that time, the technology will improve the supply chain or not, there is the decentralized management system or not, supply chain member pressure and there is uniform standardization or not. The cost and benefit consideration is the most discussed factor among the sample literature that is used in this paper.

The common practice in developing economies in Asia is still lag in developing and implementing food safety and traceability standard thus limit exports of food products. Poor regulation of chemical use, pollutants, and a steep learning curve in traceability capacity still restrict grower's and processor's participation. Implementing the adoption of RFID to increase the traceability of the food supply chain, still need to have some efforts toward the challenges, especially in the costs that relate to the traceability system that will be used.

Constructing good, efficient, and useable traceability systems will be a long-term task for every company that decides to apply the traceability systems in its supply chain. They may be required to have a good financial capability and available traceability resources. With the help of computer and internet connection, they may establish a central database can coordinate information connectivity and make us easy to access and share information. This is also will be such an achievement for the integrated supply chain management for food security and food safety in improving efficiency and coordination.

\section{Conclusions and suggestions for future research}

Developing and implementing a full chain of food traceability system just like RFID in the food industry is a complex task that requires more innovations. To achieve a good implementation of food traceability system in order to preserve the sustainability of food security and food safety we can do it by developing effective and efficient traceability technologies and innovative food supply chain management. Improving food supply chain management will be significant if we can provide training to improve the skill, awareness, and motivation of employee.

Based on the analytical results, we propose some imaginations for future studies. First, from the results of citation and journal distribution analyses (i.e. Table 1 and 2), we could see that the research community of RFID (and similar technology) in food supply chain has not been organized well. Scholarly collaborations are fewer than other mature literature in the food supply chain research streams. Future scholarly works can give courageous trial on cross-boundary collaborative research and add more communications among different studies (and their findings). Second, since the current works have great emphases on systematic view of how RFID works in the supply chain. As we have mentioned above, more works that brings business model thinking are required, in order to turn the power of technology to market values. More empirical studies designed from such angle would be very important to provide theoretical improvement and practices design. Third, as observed in the categorization of research topic (e.g. Table 4), most existing studies emphasized exploration for the antecedents for the decision and effectiveness of adopting RFID. Future studies could focus more on searching for strategic outcomes of RFID implementation. Last but not least, we can also encourage more researches on integrated traceability systems and further development of user-friendly traceability tools and data processing software. Integrating traceability activities and food logistics activities also will be a challenge for developing a good food traceability system. Strengthening the information connectivity among partners and considering traceability issues at the early stage of designing the food logistics network 
is also important. Beside all of the factors describe earlier, there are some remarkable notes that need to be discussed further, such as, how to organize the increasing interests from society, government agencies, and researchers in the security of food supply chain and use it to attract financial funding and promotion, preparing more clear traceability guidelines to improve the implementation and ensure the quality of the information shared between actors of supply chain.

\section{Acknowledgements}

This research was supported by the National Key Research and Development Program of China (2017YFC1601700) and the Key Project of National Natural Science Foundation of China (No. 71633002).

\section{Conflict of interest}

The authors declare no conflict of interest.

\section{References}

Adley, C.C. 2014. Past, present and future of sensors in food production. Foods 3: 491-510.

Angeles, R. 2005. RFID technologies: supply-chain applications and implementation issues. Information Systems Management 22(1): 51-65.

Asif, Z. 2005. Integrating the supply chain with RFID: a technical and business analysis. Communications of the Association for Information Systems 15(1): 24.

Attaran, M. 2007. RFID: an enabler of supply chain operations. Supply Chain Management: an International Journal 12(4): 249-257.

Aung, M.M. and Y.S. Chang. 2014. Traceability in a food supply chain: safety and quality perspectives. Food Control 39: 172-184.

Barge, P., P. Gay, V. Merlino and C. Tortia. 2014. Item-level radio-frequency identification for the traceability of food products: application on a dairy product. Journal of Food Engineering 125: 119-130.

Bigliardi, B. and E. Bottani. 2010. Performance measurement in the food supply chain: a balanced scorecard approach. Facilities 28(5-6): 249-260.

Bottani, E. and A. Rizzi. 2008. Economical assessment of the impact of RFID technology and EPC system on the fast-moving consumer goods supply chain. International Journal of Production Economics 112(2): 548-569.

Bowersox, D.J. and P.J. Daugherty. 1995. Logistics paradigms: the impact of information technology. Journal of Business Logistics 16(1): 65.

Boyson, S., T. Corsi and A. Verbraeck. 2003. The e-supply chain portal: a core business model. Transportation Research 39: 175-192.

Cheng, E., H. Li. P. Love and Z. Irani. 2001. An e-business model to support supply chain activities in construction. Logistics Information Management 14(1-2): 68-78.

Chesbrough, H. 2007. Business model innovation: it's not just about technology anymore. Strategy \& Leadership 35(6): 12-17.

Choe, Y.C., J. Park, M. Chung and J. Moon. 2009. Effect of the food traceability system for building trust: price premium and buying behavior. Information Systems Frontiers 11(2): 167-179.

Dabbene, F. and P. Gay. 2011. Food traceability systems: performance evaluation and optimization. Computers and Electronics in Agriculture 75(1): 139-146.

Domdouzis, K., B. Kumar and C. Anumba. 2007. Radio-frequency identification (RFID) applications: a brief introduction. Advanced Engineering Informatics 21(4): 350-355.

Garfinkel, S.L., A. Juels and R. Pappu. 2005. RFID privacy: an overview of problems and proposed solutions. IEEE Security \& Privacy 3(3): 34-43.

Hong, I.H., J.F. Dang, Y.H. Tsai, C.S. Liu, W.T. Lee, M.L. Wang and P.C. Chen. 2011. An RFID application in the food supply chain: a case study of convenience stores in Taiwan. Journal of Food Engineering 106(2): 119-126. 
Jedermann, R., L. Ruiz-Garcia W. Lang. 2009. Spatial temperature profiling by semi-passive RFID loggers for perishable food transportation. Computers and Electronics in Agriculture 65(2): 145-154.

Kelepouris, T., K. Pramatari and G. Doukidis. 2007. RFID-enabled traceability in the food supply chain. Industrial Management \& Data Systems 107(2): 183-200.

Kumar, P., H.W. Reinitz, J. Simunovic, K.P. Sandeep and P.D. Franzon. 2009. Overview of RFID technology and its applications in the food industry. Journal of Food Science 74(8): 101-106.

Landt, J. 2005. The history of RFID. IEEE Potentials 24(4): 8-11.

Manthou, V., M. Vlachopoulou and D. Folinas. 2004. Virtual e-chain (VeC) model for supply chain collaboration. International Journal of Production Economics 87(3): 241-250.

Michael, K. and L. McCathie. 2005. The pros and cons of RFID in supply chain management. In: Proceedings of the International Conference on Mobile Business. IEEE Computer Society, Washington, DC, USA, pp. 623-629.

Ngai, E.W.T., K.K. Moon, F.J. Riggins and Y.Y. Candace. 2008. RFID research: an academic literature review (1995-2005) and future research directions. International Journal of Production Economics 112(2): 510-520.

Ngai, E.W.T., F.F.C. Suk, and Y.Y. Lo. 2008. Development of an RFID-based sushi management system: the case of a conveyor-belt sushi restaurant. International Journal of Production Economics 112(2): 630-645.

Prater, E., G.V. Frazier and P.M. Reyes. 2005. Future impacts of RFID on e-supply chains in grocery retailing. Supply Chain Management: an International Journal 10(2): 134-142.

Rao, K.V.S. 1999. An overview of backscattered radio frequency identification system (RFID). In: Asia Pacific Microwave Conference. November 30 - December 3, 1999. Raffles City Convention Centre, Singapore, pp. 746-749.

Regattieri, A., M. Gamberi and R. Manzini. 2007. Traceability of food products: general framework and experimental evidence. Journal of Food Engineering 81(2): 347-356.

Roberts, C.M. 2006. Radio frequency identification (RFID). Computers \& Security 25(1): 18-26.

Sarac, A., N. Absi and S. Dauzère-Pérès. 2010. A literature review on the impact of RFID technologies on supply chain management. International Journal of Production Economics 128(1): 77-95.

Sarma, S.E., S.A. Weis and D.W. Engels. 2002. RFID systems and security and privacy implications. In: $4^{\text {th }}$ International Workshop on Cryptographic Hardware and Embedded Systems. August 13-15, 2002. Redwood Shores, CA, USA, pp. 454-469.

Tajima, M. 2007. Strategic value of RFID in supply chain management. Journal of Purchasing and Supply Management 13(4): 261-273.

Visich, J.K., S. Li, B.M. Khumawala and P.M. Reyes. 2009. Empirical evidence of RFID impacts on supply chain performance. International Journal of Operations \& Production Management 29(12): 1290-1315.

Wang, L.C., Y.C. Lin and P.H. Lin. 2007. Dynamic mobile RFID-based supply chain control and management system in construction. Advanced Engineering Informatics 21(4): 377-390.

Wang, N., N. Zhang and M. Wang. 2006. Wireless sensors in agriculture and food industry - recent development and future perspective. Computers and Electronics in Agriculture 50(1): 1-14.

Weinstein, R. 2005. RFID: a technical overview and its application to the enterprise. IT Professional 7(3): 27-33.

Weis, S.A., S.E. Sarma, R.L. Rivest and D.W. Engels. 2004. Security and privacy aspects of low-cost radio frequency identification systems. In: Proceedings of the $2^{\text {nd }}$ International Conference on Security in Pervasive Computing. April 6-8, 2005. Boppard, Germany, pp. 201-212.

Wu, N.C., M.A. Nystrom, T.R. Lin and H.C. Yu. 2006. Challenges to global RFID adoption. Technovation 26(12): 1317-1323.

Yagi, J., E. Arai and T. Arai. 2005. Parts and packets unification radio frequency identification (RFID) application for construction. Automation in Construction 14(4): 477-490.

Zelbst, P., K. Green, V. Sower and G. Baker. 2010. RFID utilization and information sharing: the impact on supply chain performance. Journal of Business \& Industrial Marketing 25(8): 582-589.

Zhang, M. and P. Li. 2012. RFID application strategy in agri-food supply chain based on safety and benefit analysis. Physics Procedia 25: 636-642.

Zhong, R., X. Xu and L. Wang. 2017. Food supply chain management: systems, implementations, and future research. Industrial Management \& Data Systems 117(9): 2085-2114. 
